\title{
THE QUESTION OF OBJECTIVITY, ITS IMPLICATIONS FOR THE SOCIAL SCIENCES IN THE ERA OF POSTMODERNISM: AFRICA IN PERSPECTIVE
}

\author{
Augustine Akwu ATABOR, PhD \\ University of Nigeria, Nsukka
}

\begin{abstract}
This paper problematizes the question of objectivity as it pertains to the social sciences. The paper accentuates the difficulty with postmodernism which tries to deny the possibility of objective truth in the social sciences. Thus, the main objective of this paper is to evaluate the postmodernists' quest for relativity and subjectivity of truth and to expose whether objectivity is attainable in the social sciences in the same way it is attainable in the natural sciences. This paper upholds that objectivity in the social science is important in working out a holistic global ideology, and since this global ideology hopes to provide for and project justice and respect for persons and communities as well as provide a basis for the minimizing and resolving of conflicts locally and internationally, Africa can on this grounds dare to be part of this global project without fear of playing a "western script" called globalization.
\end{abstract}

Keywords: Modernism, postmodernism, Social Science, Hermeneutics, Objectivity

\section{Introduction}

The postmodern controversy of objectivity in the social sciences raises questions that pertain to the deepest dimensions of our being and humanity: how we know what we know, how we should think about individual endeavor and collective aspirations, whether progress is meaningful and how it should be sought. Postmodernism questions causality, determinism, egalitarianism, humanism, liberal democracy, necessity, objectivity, rationality, responsibility and truth. It takes on issues that are profoundly fundamental for the future of social science (ROSENAU 1992, 1). The emergence of post-modernism may simply reflect intellectual currents in the larger society, but in the social sciences it also reacts to uncritical confidence in modern science and smugness about objective knowledge.

Historically, science attacked the arbitrary authority of church and monarchy, both of which based their legitimacy on theology. Modern science established its reputation on objectivity, rigorous procedures of inquiry, the material rather than the metaphysical. Science, in turn, came to claim its own monopoly of truth. Its authority expanded and superseded that held by its more “irrational and arbitrary" antecedents (ROSENAU 1996, 9). Post-modernists call 
to question the rational base of this monopoly of truth ascribed to the sciences and are uneasy with their more conventional colleague's uncritical acceptance of philosophical foundationalism, the Enlightenment heritage, and the methodological suppositions of modern science.

Postmodernism haunts social science today in a number of respects, some plausible and some preposterous, post-modern approaches dispute the underlying assumptions of mainstream social science and its research product over the last three decades. The challenges post-modernism poses seem endless. It rejects epistemological assumptions, refutes methodological conventions, resists knowledge claims, obscures all versions of truth, and dismisses policy recommendations (ROSENAU 1996, 3). Post-modernism represents the coming together of elements from a number of different, often conflicting orientations. It appropriates, transforms, and transcends French structuralism, romanticism, phenomenology, nihilism, populism, existentialism, hermeneutics, Western Marxism, Critical Theory, and anarchism. Although post-modernism shares elements with each, it has important quarrels with every approach (ROSENAU 1996, 13).

It is against this background that this paper is out to argue that the social sciences have a right claim to objectivity and that they have much to offer in the endless struggle to enhance the human condition. Thus, it is important to explore the postmodern perspective of the social sciences and to critically evaluate their claims as this would build a fertile ground upon which Africa can be part of the global ideology for justice, peace and fairness. However, let us first clarify some important terms to make the objectives of this paper more explicit.

\section{Postmodernism}

Postmodernism according to Eva Brann can be deconstructed in a tripartite fashion; Post-modern-ism. Its first syllable, "post", does not mean simply "after" in time, as period prefixes often do. The "post" in this term, says Lyotard, one of the leading definers of the movement, intends the Greek preposition "ana," which as a prefix can mean "back again," as in anamnesis, - re-collection. Recollection is not mere recall, but effective re-appropriation of memory (1992, 5). Lyotard goes further to say; "The postmodern would have to be understood according to the paradox of the future (post) anterior (modo)" (BRANN 1992, 5). He means that in a postmodern work, the future comes "after" the "just now" in the sense that; such a work is not composed in accordance with any previous universal rules, or, as he calls it, any "metanarrative." It has no antecedently present conditions. He views postmodernism as incredulity toward metanarratives. This definition is made with reference to the term "modern" which designates "any science that legitimates itself with reference to a metadiscourse, such as, the dialectics of spirit, the hermeneutics of meaning," or, I 
might add, the shared rationality of minds. Thus, the "post" makes reference both to the readmission of history by anamnesis and to the definitive exclusion of metaphysics and its derivatives. The sawing through of the perch we sit on, the undermining of the structures we rely on, is to be taken in the most total sense; "Nothing is to support anything" (BRANN 1992, 6).

The second element, "modern," is a coinage of the sixth century (AD). It comes from the Latin word modo, meaning "just now" or "this moment." It is a word needed, now as then, when an epoch is felt to have been superseded by the present, the up-to-date. It betokens a sense of having left something behind and of being on the cutting edge of time. It is a term of temporal self-location. There have been many modernisms: theological, national, aesthetic, literary, architectural. In fact, one might say that modernity is the propensity to modernisms; I mean the urge of elites not only to be continually displacing the late by the latest, but to induce "movements" that is, a tendentious drift, in followers (BRANN 1992, 4).

The final element is the "ism" or the personal form "ist." It is a Greek and Latin ending, connoting the adoption, often perverse or specious, of the habits of a group. For example, barbarism is a behavior like that of those who babble inarticulately, and a sophist is one who looks like a wise man, a sophas, without having or loving wisdom, in opposition to a philosophos. Whether for good or ill, "ism" connotes running in droves, and an 'ist' is an intellectual assimilationist (BRANN 1992, 4).

Having done this tripartite deconstruction, what then is postmodernism? According to Terry Eagleton, postmodernism is "a style of thought which is suspicious of classical notions of truth, reason, identity and objectivity, of single frameworks, grand narratives or ultimate grounds of explanation" (1996, vii.). Thus, from this definition, it could be sustained that; postmodernism is a drive towards some form of relativism or subjectivism. A movement that is out to question every convention and tradition and most importantly for this paper, it is a movement that questions the grounds of the social sciences' claim for objectivity. As a reaction on modernism, postmodernism emerged in academic studies in the mid-80's of last century. It can be seen as a worldview that emphasizes the existence of different worldviews and concepts of reality, rather than one 'correct' or 'true' one. Whereas modernism emphasized a trust in the empirical scientific method, and a distrust and lack of faith in ideologies and religious beliefs that could not be tested using scientific methods, postmodernism emphasizes that a particular reality is a social construction by a specific group, community or class of persons. 


\section{The Social Sciences}

Social science is a group of academic discipline that examines society and how people interact and develop as a culture. Social science as a field of study is separate from the natural sciences, which covers topics such as physics and chemistry. Social science as an academic field of study, developed out of the age of enlightenment as individuals began to take a more disciplined approach to quantifying their observations of society. Over time, similar aspects of the society, such as communication, were separated into unique fields of study.

\section{Objectivity}

Diana Mertz views objectivity as a method of acquiring knowledge by reasoning solely based on the facts of reality and in accordance with the laws of logic (2013, Web. N. P.). Objectivity is a central philosophical concept related to reality and truth which has been variously defined by sources. Generally, objectivity means the state or quality of being true even outside of a subject's individual feelings, imaginings or interpretations. A proposition is generally considered to be objectively true (to have objective truth) when its truth condition are met and are "mind-independent" - that is, existing freely or independently from a mind (from the thoughts, feelings, ideas etc. of a sentient subject). In a simpler meaning of the term, objectivity refers to the ability to judge fairly without bias or external influence that occurs in a phenomenological way (Web, N. P.).

\section{Historical Origins of Postmodernism}

The post-modern turn is not native to North America; rather, it is an adopted child of continental Europe, predominantly of French and German descent. As one important French intellectual smugly points out, post-modernism and poststructuralism sell as well in the North American intellectual market as "Beaujolais Nouveau." The irony is that, although the French get most of the credit for developing post-modernism, German philosophers, mainly Nietzsche and Heidegger, inspired it. Despite this intellectual debt, contemporary German philosophers, especially Jürgen Habermas, are among post-modernism's most severe critics. But post-modernism is not always received so sympathetically in France either. Important French post-modernists, particularly Jacques Derrida, have of late lost credibility in their own country. Nevertheless the appeal of postmodernism continues to grow outside France (ROSENAU 1992, 12).

Postmodernism emerged from the existentialist and phenomenologist philosophies of, amongst others, Nietzsche, Heidegger and Husserl. It is unsurprising, then, that it has many features in common with social phenomenology and ethnomethodology, which share some of the same philosophical precursors. While these approaches were more methodologically 
inclined than postmodernism, they similarly rejected the Enlightenment attempt to create universal knowledge, preferring to emphasis subjective meaning and to problematize everyday occurrences (AGGER 2013, 117).

\section{Affirmative and Skeptical postmodernism}

The divergent, even contradictory expositions of post-modernism underline the need to distinguish among its various orientations, if we are ever to be able to talk about it at all. There are probably as many forms of post-modernisms as there are post-modernists (FEATHERSTONE 1998, 207). If it were not so clumsy, we could speak of post-modernisms. But, within this diversity of postmodern pronouncements, as far as the social sciences are concerned, two broad, general orientations, the skeptical post-modernists and the affirmative postmodernists, can be delineated (ROSENAU 1992, 15).

Inspired by Continental European philosophies, especially Heidegger and Nietzsche, skeptical postmodernism is the dark side of postmodernism, the postmodernism of despair, the postmodernism that speaks of the immediacy of death, the demise of the subject, the end of the author, the impossibility of truth, and the abrogation of the Order of Representation. Post-modernists of this orientation, adopt a blasé attitude, as if "they have seen it all" and concluded that; nothing really new is possible (GITLIN 1989, 103). The skeptical postmodernism (or merely skeptics), offering a pessimistic, negative, gloomy assessment, argue that; the post-modern age is one of fragmentation, disintegration, malaise, meaninglessness, vagueness or even absence of moral parameters and societal chaos (SCHERPE 1986, 101).

According to Rosenau, the affirmative postmodernism which is more indigenous to Anglo-North American culture than to Europe, has a more general optimistic view of the post-modern age. The generally optimistic affirmatives are oriented toward process. They are either open to positive political action (struggle and resistance) or content with the recognition of visionary, celebratory personal non-dogmatic projects that range from New Age religion to new wave life-styles and include a whole spectrum of post-modern social movements. Most affirmatives seek a philosophical and ontological intellectual practice that is nondogmatic, tentative, and non-ideological (ROSENAU 1992, 15).

\section{The Social Studies as a Science and the Question of Objectivity}

To be scientific would entail a level of systematic and disciplined method of enquiring knowledge and that knowledge must be a verifiable knowledge. This brings to fore the question; whether the society, its institutions and relationships are susceptible to scientific study? Allusions to the fact that the terms "social" and "scientific" may not sit comfortably together, was illustrated by the decision of the British Government in the early nineteen eighties to change the name of 
the Social Science Research Council (which included mass communication research in its remit) to the Economic and Social Research Council. The message seemed to be: if it is social, it can't be scientific" (HALLORAN 1998). However, this position remains a point of debate as other persons are ready to classify both the natural and social sciences in terms of methodology under the unity of scientific method.

The achievements of the natural sciences in the wake of the scientific revolution of the seventeenth Century have been most impressive. Their investigation of nature has produced elegant and powerful theories that have not only greatly enhanced understanding of the natural world, but also increased human power and control over it. Modern physics for instance, has shed light on such mysteries as the origin of the universe and the source of the sun's energy, and it has also spawned technology that has led to supercomputers, nuclear energy (and bombs), and space exploration. Natural science is manifestly progressive, insofar as, over time its theories tend to increase in- depth, range and predictive power. It is also consensual, that is, there is a general agreement among Natural Scientists regarding what the aims of science are and how to conduct it, including how to evaluate theories. At least, in the long run, Natural Science tends to produce consent regarding which theories are valid. Given this evident success, many philosophers and social theorists have been eager to import the methods of Natural Science to the study of the social world. If social science were to achieve the explanatory and predictive power of Natural Science, it could help solve vexing social problems, such as violence and poverty, improve the performance of institutions and generally foster human well-being. Those who believe that adapting the aims and methods of Natural Science to social inquiry is both possible and desirable, support the unity of scientific method. Such advocacy in this context is also referred to as naturalism. Of course, the effort to unify social and natural science requires reaching some agreement on what the aims and methods of science are (or should be). A school of thought, broadly known as positivism, has been particularly important here. Despite the collapse of positivism as a philosophical movement, it continues to exercise influence on contemporary advocates of the unity of scientific method. (GORTON 2013, Web N. P.).

However, it must be known that postmodernism has a lot of issues with positivism and the postmodernists' criticisms of positivism has its implications for the social sciences, at least on the question of objectivity. This is so because if the social sciences were only to be objective when the methods of the natural sciences are imported into its modes of inquiry, then the attack of postmodernism on positivism is an attack aimed at the possible claims of objectivity by the social science. 
It is a fact that many social scientists are driven to often rely implicitly upon the positivists' tenets that experience is the basis of knowledge and it is possible to reflect the world objectively, without relying upon philosophical and theoretical assumptions. The use of 'positivistic attitude' here refers to approaches that involve any of these suppositions: that the methods of the natural sciences may be directly adapted for the social sciences; that the role of the political analyst is that of an impartial observer of social reality; that the goal of political analysis is to formulate law-like generalizations; that knowledge and language are purely instrumental.

Postmodernism has done much to challenge this positivistic attitude in the social sciences. Michel Foucault, a key postmodern thinker (although he rejected the label), is noted for his appraisal of the social sciences. He dismissed social scientists' claims to objectivity and neutrality by showing how they conflated moral and legal norms into scientific truth. For example, Foucault asserted that crime was judged against a scientific 'knowledge' of what was normal, and that punishment had come to be legitimated as much by social science as by the legal system. Deviations from the law came to be seen as offences against 'objectively' known human nature (AMERY 2008, 6).

According to Amery, Foucault specifically expanded Nietzschean historic philosophy in order to question beliefs and aspects of everyday life such as madness or sexuality - thought to be timeless. Through this technique of 'genealogy' he was able to trace the development of present-day institutions and ideas and to show that they were grounded in history rather than the ahistorical notions of Reason and Truth. For example, Foucault argues that the modern experience of madness, rather than being grounded in unchanging scientific fact, has its roots in the 'Great Confinement' of the seventeenth century, when 'unreasonable' members of the society were placed in asylums $(2008,6)$.

Jacques Derrida, although he differed from Foucault in important ways, advanced an equally significant critique of positivism. To Derrida, all discourses, including supposedly scientific reports, rely on concealed assumptions and cannot be understood without them. (AGGER 2013, 112). As with Foucault, these texts also present a certain view of the world as objective truth. Thus, traditional status-attainment research which defined social mobility in terms of the occupational status of one's father was far from neutral: it presented a view of the social world where only men worked or should work, and in fact misrepresented reality by ignoring women who worked. (AGGER 2013, 113) Derrida pioneered the technique of 'deconstruction' in order to expose the hidden assumptions of texts. 


\section{Postmodernism, the Social Science and the Politics of Globalization}

The term Globalization could mean different thing to different people. For some, globalization entails the Westernization of the world, while for others it involves a cover for the ascendancy of capitalism. Some see globalization as generating increasing homogeneity, while others see it producing diversity and heterogeneity through increased hybridization. For business, globalization is a strategy for increasing corporate profits and power, for government it is often deployed to promote an increase in state power, while non-government social organizations see globalization as a lever to produce positive social goods like environmental action, democratization, or humanization. Many theorists equate globalization with modernity, while others claim that the "global age" follows and is distinctly different from the "modern age." Indeed, for some theorists, we live in a global age or epoch, in which globalization is the defining concept, while others find claims for the novelty and centrality of globalization exaggerated.

Though, one cannot claim ignorance of the politicization of globalization, however, the need for the world to have a global ideology that would provide for and project justice and respect for persons and communities as well as provide a basis for the minimizing and resolving of conflicts locally and internationally has become increasingly clear. While it is believed that the social sciences will provide the framework and grounds to achieve this objective, the postmodernists' attack on the plausibility of the claims of objectivity by the social sciences, remains a big challenge.

Postmodernists have highlighted how much political theory and research ignores or relegates certain social groups to the sidelines, furthering their disempowerment. All theories, they argue, come from a particular standpoint, and in the Western world, the dominant standpoint has often been that of a white, heterosexual man. As demonstrated above, these theories have the power to present their views of the world as scientific truth, and thus legitimate a social and political order where certain groups are marginalized or oppressed (AMERY 2008, 7). According to Foucault, the state works hand in hand with other institutions of the modern world - prisons, schools, medical clinics and the military - to monitor and control people. It accomplishes this, however, neither principally through brute force nor via a regiment of rewards and punishments. Rather, the state works in concert with social science to construct the very categories through which individuals understand themselves. In doing so, it establishes the criteria by which normal and abnormal behavior is understood, and thereby regulates behavior, most importantly, by getting people to regulate themselves. In this way, social science has in effect become a handmaid to the forces of domination rather than a potential source of emancipation. Significantly, Foucault never claimed that this new type of control is intentional. 
It is merely an unwelcomed artifact of social science. (GORTON 2013, Web. N. P.).

Thus, while Modernism was Universalist in outlook, much of its universalism was the universalization and the projection of the values/ideology of a particular class, ethnic group or culture and this constitutes one of the major critique of modernism by postmodernists; who pointed out that the creation of ideas, truth and knowledge are context-based and confined to contexts. It is in this regard that we bring in the perspective of Africa in this paper. How much of African life-world is represented in the so-called global matrix of modernity? The evident absence of the African perspective in the modern dynamics readily makes the postmodern ideology an attraction for the African intelligentsia. Postmodernism is deeply relativist; it undermines universalism; and, is itself unable to provide a common frame of reference that will help in solving the world's problems such as violence and conflicts, the integration of peripheral economics into the global economy but it at least, demolishes modernity which seeks to impose the culture of a determined race on the rest of humanity which includes Africa.

\section{Africa and Globalization}

It is not for no reason that the African man is suspicious of the idea of globalization which is one of the features of the postmodern era. According to Ike Obiora, Africa has experienced globalization in four phases; the first stage which has to do with slavery, robbed the continent of some of its citizens, at the second stage, colonialism came with its exploitative and divisive alien patterns, at the third stage is the experience of neo-colonial political pressures and economic forces that set trade patterns, investment policies, debt arrangement and others, the fourth stage is what is rather branded today as globalization (2014, 23). All this, have contributed in painting the idea of globalization wrongly, hence the painful African memory. It is a fact that with the rate of technological advancement in the world, the world has rather become a global family. The reality of this development has made it important that there be global ideologies that govern human rights and actions. However, as important as this may sound, Africa has come to believe that there is always a western agenda that is being preached in the name of globalization, though this is not without some element of truth, this paper has tried to show that with findings garnered from the social science regarding those basic and common concerns of humanity, a global ideology could be arrived at. This version of globalization, it is hoped would be inclusive rather than exclusive of some cultures as the modern global matrix had done. It may therefore be assumed that the difficulty of arriving at objectivity and a truly universal truth was due to the lopsided nature of the modern global matrix. In a postmodern era, where relative conception of truth is imperative and 
a culture-based objectivity clearly inevitable, it remains not just a possibility but a practical expectation that cross-cultural reasoning would pave the way and create interlinking corridors across cultures. These shall be the areas of common grounds pertaining to the universal agreement of human reason. Thus, even in the relativity and culture-based objectivity of postmodernism, there may be room even in the social sciences for a form universal objectivity and truth.

\section{Conclusion}

It is my contention that though all-round objectivity in the social science is difficult, aiming at it, or attaining as much of it as reasonably possible, is a necessary condition for the conduct of all scientific inquiry. Why should we consider complete objectivity so important that we should pursue it even when admitting it to be somehow inaccessible? In my opinion, viewing inquiry as subjective, or as an entirely individual matter, would be the exclusion of all criticism; and this would be the exclusion of rational debate; and the exclusion of some cultures like Africa; and this would also be the denial of the thesis of the intellectual or rational unity of mankind. It thus opens the door to irrationalism and elitism, whether social or racial.

It is ordinarily expected that no matter the diversities in terms of race, nationality, ethnicity, culture and language among men, there will remain to be some common grounds of our shared humanity. Furthermore, it is becoming increasingly clear that it is necessary for the world to have a global ideology that would provide for and project justice and respect for persons and communities as well as provide a basis for the minimizing and resolving of conflicts locally and internationally. It is hoped that within the quest for this objective, Africa will not be marginalized either directly or indirectly.

\section{Relevant Literatures}

1. AGGER, Ben. "Critical Theory, Post Structuralism, Postmodernism: Their Sociological Relevance," [Annual Review of Sociology], Pp.105-31, 1991. Retrieved. 2013. No 17. Web.

2. AMERY, Frann. "Allowing the Other to Speak: The Relevance of Postmodernism to Political analysis", [Reinvention: An International Journal of Undergraduate Research], Web, N. P., 2008. Vol. 1, Issue 2. Retrieved, August, 2014. Web. 
3. BRANN, Eva. "What is Postmodernism?", [Harvard Review of Philosophy]. Pp.1-10, spring, 1992. Retrieved, July, 2014. Web.

4. EAGLETON, Terry. [The Illusions of Postmodernism], 1996. Blackwell Publishers: Oxford. E-book.

5. FEATHERSTONE, Mike. "In Pursuit of the Postmodern: An Introduction," [Theory, Culture and Society]. Pp.195-207, June, 1998. Vol. 5. No. 2. Retrieved July 2014.Web.

6. GORTON, William. "Philosophy of the Social Sciences", [Internet Encyclopedia of Philosophy], Web, N. P, N. D. Retrieved $26^{\text {th }}$ July, 2013. Web.

7. GITLIN, Todd. "Postmodernism: Roots and Politics", [Dissent], Pp.100-108, winter, Jul/Aug 1989. Retrieved July, 2014. Web.

8. HALLORAN, J. D, "Social Sciences, Communication Research and the Third World," [Media Development], 1998. Vol. 2, WACC. Retrieved July, 2014. Web.

9. HSIEH, Diana. "What is Objectivity?", [Find Enlightenment], June 1999. Retrieved July $26^{\text {th }}$, 2013. Web.

10. OBIORA, Ike and EDOZIEN, Ndidi Nnoli. "Africa in the Age of Globalization: The Challenges of Culture Identity in an interdependent World," [Globalization and African SelfDetermination: What is the Future? OBIORA, Ike Ed]. Pp.21-28, 2014. Catholic Institute for Development, Justice and Peace printing and Publishing House: Uwani, Enugu. Paperback. 
11. ROSENAU, Pauline. [Postmodernism and the Social Sciences: Insights, Inroads and Intrusions], 1992. Princeton University Press: Princeton. E-book.

12. SCHERPE, Klaus. "Dramatization and De-dramatization of the End: The Apocalyptic Consciousness of Modernity and Postmodernity", [Cultural Critique], Pp.95-129, winter 1986-87. No.5. Retrieved July 2014. Web. 